\title{
Incidences of Hepatitis B and Syphilis Co-Infection with HIV in Antiretroviral Treatment-Naïve Adult Patients Attending APIN Clinic at a University Teaching Hospital in Lagos, Nigeria
}

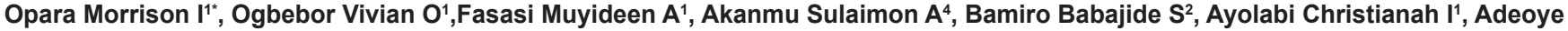
Grace $\mathbf{O}^{3}$ and Adeleye Isaac $\mathrm{A}^{1}$

${ }^{1}$ Department of Microbiology, University of Lagos, Akoka, Lagos State, Nigeria

${ }^{2}$ Department of Obstetrics and Gynecology Research Laboratory, College of Medicine, University of Lagos, Idi-Araba, Lagos State, Nigeria

${ }^{3}$ Department of Zoology, University of Lagos, Akoka, Lagos State, Nigeria

${ }^{4}$ Department of Hematology and Blood Transfusion, College of Medicine, University of Lagos, Idi-Araba, Lagos state, Nigeria

\begin{abstract}
Hundred (37 males and 63 females) sera samples of HIV patients were screened for hepatitis B antigens and antibodies, and 80 (28 males and 52 females) of these samples were also screened for Treponema specific antibodies using ELISA. Seven percent ( $5 \%$ males and $2 \%$ females) were positive for hepatitis B surface antigen $(\mathrm{HBsAg})$. Four percent ( 3 males and 1 female) of the latter were also positive for the hepatitis $\mathrm{B}$ envelope antigen (HBeAg). While $5 \%$ (1\% male and $4 \%$ female) were positive for hepatitis $B$ surface antibody, $7 \%$ ( $1 \%$ male and $6 \%$ female) were positive for hepatitis B envelope antibody ( $\mathrm{HBeAb}$ ). Twenty three percent ( $8 \%$ males and $15 \%$ females) were positive for hepatitis $B$ core antibody $(\mathrm{HBCAb})$. Thirty seven percent of the patients have had previous exposure to hepatitis $B$ virus as shown by positive results obtained for $\mathrm{HBsAg}, \mathrm{HBcAb}$ and $\mathrm{HBeAb}$. The mean $\mathrm{CD} 4^{+}$counts for positive samples were 228 for HBsAg, 3278.5 for HBeAg, 199.5 for HBsAb, 194 for HBeAb and 232.5 HBcAb. Twenty percent $(10 \%$ males and $10 \%$ females) of the patients were positive for the syphilis antibodies. The mean CD4 ${ }^{+}$counts for the positive samples for syphilis were 290.5 . The $7 \%$ prevalence of hepatitis B virus observed in this study is within the rates that had been previously reported, but the $20 \%$ prevalence of syphilis is high. This calls for a review of screening regimen that would assay for these bloodstream infections alongside HIV, in order to mitigate any influence they may have in the progression of HIV to AIDS.
\end{abstract}

Keywords: Hepatitis B; Syphilis; Co-infection; HIV; ARV treatmentnaïve; APIN clinic

Abbreviations: HIV: Human Immunodeficiency Virus; APIN: AIDS Prevention Initiative in Nigeria; ELISA: Enzyme Linked Immuno Sorbent Assay; CD4: Cluster of Differentiation 4; AIDS: Acquired Immune Deficiency Syndrome; ARV: Anti Retroviral; HBV: Hepatitis B Virus; DNA: Deoxyribonucleic Acid; STD: Sexually Transmitted Diseases; VCT: Voluntary Counseling and Testing; HAART: Highly Active Antiretroviral Therapy

\section{Introduction}

The association between HIV, HBV and sexually transmitted disease (STDs) has been established. The Hepatitis B Virus (HBV) and Human Immunodeficiency Virus (HIV) are viruses that share certain epidemiological characteristics such as risk populations and transmission routes with syphilis. This puts HIV positive individuals at risk of co-infection with hepatitis B or syphilis or both. For HIV and $\mathrm{HBV}$ co-infection (HIV/HBV), the sero prevalence ranges from $6.3 \%$ to as high as $39 \%$ [1-3] while values as high as $27.5 \%$ and $12.4 \%$ have been reported for men and women for syphilis respectively [4].

In areas of low endemicity, such as North America, Australia and Europe, HBV and HIV infection are usually acquired in adulthood through sexual or percutaneous transmission and the prevalence of chronic co-infection is around 5-7\% [5]. In countries with intermediate and high HBV endemicity, the main routes of transmission of HBV are perinatal or in early childhood. In these countries, HBV co-infection rates are $10-20 \%$ [6-8]. The rate of progression and complications from viral hepatitis has been reported to be accelerated in patients with HIV co-infection $[9,10]$. HIV/HBV co-infected individuals are 6 times more likely to develop chronic hepatitis B than HIV negative individuals [11-
13] and this is more likely to occur in HIV infected men with lower $\mathrm{CD}^{+}$cells [12]. Decreased rates of clearance of HBeAg and increased HBV replication are also seen, with higher HBV DNA viral load [1416]. In addition, HIV infected individuals are more likely to lose previously developed protective anti-HBs antibody and develop acute hepatitis B infection; this risk is also associated with lower $\mathrm{CD} 4^{+}$counts $[17,18]$. However, it has been established that hepatitis B infection does not hasten HIV disease progression or severity [19].

Studies have shown that the clinical manifestations of certain STDs such as syphilis facilitate the transmission of HIV [20,21]. With syphilis, there is an increase in the shedding of HIV in coinfected individuals [22], because of the presence of a chancre which provides a mechanical break in the protectective skin barrier, allowing access to the spread of HIV. Griemberg et al. [23] reported a prevalence of $8.7 \%$ of HIV/ syphilis co-infection in a study conducted in Argentina. According to their report, the prevalence of syphilis among HIV infected persons was almost twofold higher in men than women $(67.7 \%$ vs. $36.0 \%, \mathrm{p}=0.020)$. In Nigeria, the prevalence of syphilis infection among HIV patients has

*Corresponding author: Opara Morrison I, Faculty of Science, Department of Microbiology, University of Lagos, Akoka, Yaba, Lagos State, Nigeria, Tel: +234803-571-6464, +234-807-470-6302; E-mail: oparamorrison@gmail.com

Received December 03, 2012; Accepted January 17, 2013; Published January 22, 2013

Citation: Opara MI, Ogbebor VO, Fasasi MA, Akanmu SA, Bamiro BS, Ayolabi Cl, et al. (2013) Incidences of Hepatitis B and Syphilis Co-Infection with HIV in Antiretroviral Treatment-Naïve Adult Patients Attending APIN Clinic at a University Teaching Hospital in Lagos, Nigeria. J AIDS Clin Res 4: 191. doi:10.4172/2155-6113.1000191

Copyright: (C) 2013 Opara MI, et al. This is an open-access article distributed unde the terms of the Creative Commons Attribution License, which permits unrestricted use, distribution, and reproduction in any medium, provided the original author and source are credited. 
Citation: Opara MI, Ogbebor VO, Fasasi MA, Akanmu SA, Bamiro BS, Ayolabi Cl, et al. (2013) Incidences of Hepatitis B and Syphilis Co-Infection with HIV in Antiretroviral Treatment-Naïve Adult Patients Attending APIN Clinic at a University Teaching Hospital in Lagos, Nigeria. J AIDS Clin Res 4: 191. doi:10.4172/2155-6113.1000191

Page 2 of 4

been estimated to be in the range of $0.4 \%-2.7 \%$ depending on the risk population. The highest syphilis prevalence $(2.7 \%)$ has been detected among the armed forces [24].

This research is therefore an attempt to further investigate the incidences of HBV and syphilis co-infection with HIV among antiretroviral treatment-naive patients with a view to determine the prevalence of these bloodstream pathogens in these patients.

\section{Materials and Method}

\section{Study centre}

The research was carried out in a non-governmental AIDS clinic; Aids Prevention Initiative in Nigeria Clinic. The clinic is a referral centre saddled with the responsibility of counselling, testing and providing care and support for the HIV patients and has a yearly patients' enrolment of over 1000 .

\section{Ethical approval}

The ethical issues pertaining to being reviewed by the Ethics and Research Committee of the Lagos University Teaching Hospital (LUTH).

\section{Recruitment of study subjects}

One hundred HIV patients comprising 37 males and 63 females, aged between 18-60 years, who were first time attendees at the clinic between April, 2011 and March, 2012 were recruited into the study. Some of these patients came for VCT, while others were on referral from various health facilities within the locality of the teaching hospital. Standardized questionnaire was administered to the patients after obtaining their informed consent. Information on other parameters such as $\mathrm{CD}^{+}$counts and viral loads were obtained from medical records of the clinic.

\section{Inclusion/exclusion criteria}

Male and female patients who had attained 18 years or above were tested and confirmed HIV positive by the screening protocols of the clinic. Those that were yet to commence anti-retroviral treatment at the time of blood sample collection were considered eligible for the study, while those already on antiretroviral treatment were excluded.

\section{Statistical analysis}

The Statistical Package for the Social Sciences (SPSS, version 10.0, Chicago, IL, USA) was used to calculate mean values and percentages.

\section{Screening of patients}

The patients were screened for HIV 1 and 2 by the clinic using the Alere $^{\mathrm{Tm}}$ HIV land 2 Determine ${ }^{\mathrm{Tm}}$ kits (Cat. NO. 7D2342, 7D2343; Alere Medical Co., Ltd, Chiba, Japan).

Presumptive positive samples were confirmed (double-checked) with the Uni-Gold ${ }^{\mathrm{Tm}}$ HIV kits (Cat. No. 1206502N; Trinity Biotech PLC, Co Wicklow, Ireland).

\section{Sample collection and processing}

Five milliliters of venous blood were aseptically drawn into the plain vacutainer bottle and was allowed to stand undisturbed for $2 \mathrm{hr}$, after which it was spinned in the centrifuge at $15,000 \mathrm{rpm}$ for 5 mins. The resulting sera were aseptically transferred into another plain vacutainer bottle, properly labelled and kept for the serological assay.

\section{Assay for Hepatitis $B$ virus antigens and antibodies and syphilis antibodies}

The screening for HBV antigens (HBsAg and HBeAg), antibodies (HBsAb, $\mathrm{HBeAb}, \mathrm{HBcAb}$ ) and Syphilis antibodies were done using Enzyme Linked Immunosorbernt Assay (ELISA) (Biotec Labouratories Soffolk,UK) and EIAgen Syphilis New Generation ELISA kits (Cat. No.081043/081044; Adaltis Italia S.p.A) respectively. Before running the assay, all samples and reagents were allowed to warm up to ambient temperature.

\section{Procedure}

Each sera sample was diluted to final concentration of 1:100 by adding $10 \mu \mathrm{l}$ of the serum to $1 \mathrm{ml}$ of the sample diluents. The microtitre plate was appropriately labelled and $100 \mu \mathrm{l}$ of the diluted samples were then placed into the wells of the microtitre plates in duplicate, negative and positive controls were also set up by pipetting $100 \mu \mathrm{l}$ into respective wells in duplicate. (The inside of the microtitre plates were already coated with the hepatitis B antigens or antibodies and syphilis regains, which constitutes the solid phase, depending on which of the marker is being assayed for). The plate was then incubated for $30 \mathrm{~min}$ at $37^{\circ} \mathrm{C}$, after which the wells were washed with the buffered washing solution (care being taken to avoid cross-contamination during flicking). The washing step was repeated up to 5 times in order to remove unbound antibody or antigen as the case may be. The plate was drained by inverting it over an absorbent tissue paper, after which $50 \mu$ of the enzyme conjugate was added to all the wells. This was followed by another round of incubation at $37^{\circ} \mathrm{C}$ for $30 \mathrm{~min}$, washing and draining as described above. Thereafter, $50 \mu \mathrm{l}$ of the chromogen (enzyme substrate) was dispensed into each of the wells, and the plate was allowed to incubate at ambient temperature for $15 \mathrm{~min}$, during which period, the color develops. The color development was aborted by the addition of $50 \mu$ l of the stopping reagent into each well; the plate was then marked for orientation and fed into the ELISA reader where the absorbance (optical density) of each well was read at $450 \mathrm{~nm}$ within $10 \mathrm{~min}$ of stopping the reaction.

All assays were run in duplicate. The Cut off value for each batch was calculated using the mean optical densities (M. O. D) of the negative control according to the manufacturer's instruction. This cut off value was then used to calculate the activity index for each sample by dividing the MOD of each sample with the cut off value. Samples with activity index values higher or equal to those of positive control were considered positive, while those with values below were reported as negative.

\section{Results}

Table 1 shows the distribution of the patients screened for HBV and syphilis according to sex and age range. Sixteen percent of the patients were within the age range $18-27,47 \%$ within $28-37,28 \%$ within $38-47$, $8 \%$ within $48-57$ and $1 \%$ was above 57 . The results obtained for the

\begin{tabular}{|l|c|c|c|c|}
\hline \multirow{2}{*}{ Age Range } & \multicolumn{2}{|c|}{$\begin{array}{c}\text { Number screened for hepatitis B } \\
\text { virus antigens and antibodies }\end{array}$} & \multicolumn{2}{|c|}{$\begin{array}{c}\text { Number screened for syphilis } \\
\text { antibodies }\end{array}$} \\
\cline { 2 - 5 } & Male (\%) & Female (\%) & Male (\%) & Female (\%) \\
\hline $18-27$ & $1(1 \%)$ & $15(15 \%)$ & $1(1.25 \%)$ & $13(16.25 \%)$ \\
\hline $28-37$ & $11(11 \%)$ & $36(36 \%)$ & $10(12.5 \%)$ & $31(38.75 \%)$ \\
\hline $38-47$ & $17(17 \%)$ & $11(11 \%)$ & $11(13.75 \%)$ & $7(8.75 \%)$ \\
\hline $48-57$ & $8(8 \%)$ & $0(0 \%)$ & $6(7.5 \%)$ & $0(0 \%)$ \\
\hline$\geq 58$ & $0(0 \%)$ & $1(1 \%)$ & $0(0 \%)$ & $1(1.25 \%)$ \\
\hline TOTAL & $\mathbf{3 7 ( 3 7 \% )}$ & $\mathbf{6 3}(\mathbf{6 3} \%)$ & $\mathbf{2 8 ( 3 5 \% )}$ & $\mathbf{5 2}(\mathbf{6 5} \%)$ \\
\hline
\end{tabular}

Table 1: Distribution of HIV patients according to Age and Sex. 
Citation: Opara MI, Ogbebor VO, Fasasi MA, Akanmu SA, Bamiro BS, Ayolabi Cl, et al. (2013) Incidences of Hepatitis B and Syphilis Co-Infection with HIV in Antiretroviral Treatment-Naïve Adult Patients Attending APIN Clinic at a University Teaching Hospital in Lagos, Nigeria. J AIDS Clin Res 4: 191. doi:10.4172/2155-6113.1000191

Page 3 of 4

\begin{tabular}{|c|c|c|c|c|c|}
\hline \multirow[t]{2}{*}{ Assay carried out } & \multirow[t]{2}{*}{ Number of samples tested } & \multicolumn{2}{|c|}{ Number of samples positive } & \multirow[t]{2}{*}{ Total } & \multirow[t]{2}{*}{ Mean CD4+ counts of positive samples } \\
\hline & & Male (\%) & Female (\%) & & \\
\hline HBsAg & 100 & $5(5 \%)$ & $2(2 \%)$ & $7(7 \%)$ & 228 \\
\hline $\mathrm{HBeAg}$ & 100 & $3(3 \%)$ & $1(1 \%)$ & $4(4 \%)$ & 278.5 \\
\hline $\mathrm{HBsAb}$ & 100 & $1(1 \%)$ & $4(4 \%)$ & $5(5 \%)$ & 199.5 \\
\hline $\mathrm{HBeAb}$ & 100 & $1(1 \%)$ & $6(6 \%)$ & $7(7 \%)$ & 194 \\
\hline $\mathrm{HBcAb}$ & 100 & $8(8 \%)$ & $15(15 \%)$ & $23(23 \%)$ & 232.5 \\
\hline Syphilis Ab & 80 & $8(10 \%)$ & $8(10 \%)$ & $16(20 \%)$ & 290.5 \\
\hline
\end{tabular}

Table 2: Prevalence of hepatitis $B$ antigens and antibodies, syphilis antibodies and mean CD4+ counts of positive samples.

HBV (Table 2), showed that $7 \%$ of the patients comprising $5 \%$ males and $2 \%$ females were positive for HBsAg. Four percent of the HBsAg positive samples were also positive for HBeAg. Five percent comprising $4 \%$ females and $1 \%$ male were positive for HBsAb while $11 \%$ male and $6 \%$ female were positive for HBeAb. Nine percent male and $21 \%$ female were positive for $\mathrm{HBcAb}$. Thirty seven percent of the patients were positive for at least one of the HBV antigens or antibodies, while $5 \%$ had been successfully immunized as shown by the positive result for HBsAb. More positive samples for the HBV antigen and antibodies were recorded among male and female within the age range 28-37 followed by those within the age range $38-47$. While the mean $\mathrm{CD} 4^{+}$ counts for HBV positive samples were 234 for $\mathrm{HBsAg}, 336$ for $\mathrm{HBeAg}$, 165 for $\mathrm{HBsAb}, 215$ for $\mathrm{HBcAb}$, and 153 for $\mathrm{HBeAb}, 16 \%$ of the male and $33 \%$ of the female patients tested had a CD4 $4^{+}$count of less than 200. The result (Table 1), obtained for syphilis antibodies revealed that $17.5 \%$ of the patients were within the age of $18-27,51.25 \%$ were within $28-37,22.5 \%$ were within, $7.5 \%$ were within $48-57$ and $1.25 \%$ was over 57 years old. Sixteen (20\%) patients comprising $8(10 \%)$ males and 8 $(10 \%)$ females were positive for syphilis antibodies (Table 2). However, the ratio of females to males (52:28) in the sample shows that the male had a higher percent rate of the infection (28.6\%) as against $15.4 \%$ observed for female. The mean $\mathrm{CD} 4{ }^{+}$count for the positive samples for syphilis was 290.5 .

\section{Discussion}

The prevalence of HBsAg among HIV patients in this study was $7 \%$. Positive test for HBsAg suggests late incubation period of acute hepatitis and incidences of acute hepatitis among HIV patients in Nigeria had been reported [1]. Four (57\%) of the HBsAg positive samples were also positive for $\mathrm{HBeAg}$. These patients may be suffering from active or chronic hepatitis depending on their $\mathrm{HBcAb}$ results. Five percent of the patients that were positive for HBsAb have either been successfully immunized against the virus or have developed a natural immunity as a result of previous exposure to the virus. Twenty three percent and $7 \%$ of the patients that were positive for $\mathrm{HBcAb}$ and $\mathrm{HBeAb}$ respectively have had previous exposure to the virus even though they did not progress to full case of hepatitis. However, they are not immune to the virus and may eventually go on to suffer hepatitis. In all, at least $37 \%$ of the patients have had contact with virus but not all of them had clinical evidence of the infection. The $7 \%$ prevalence was slightly higher than $6.3 \%$ prevalence reported by Uneke et al. [1] in Jos, Nigeria suggesting that the viral infection may be on the increase among the population at risk. HIV and hepatitis B virus, share common mode of transmission; through sex and infected blood or blood products and greater percentage of Nigerian population do not practice safe sex through consistent use of condom. The fact that most of the study subjects (over 98\%) were categorized as heterosexual, the highest risk of the transmission for both infections among the HIV patients could be through unprotected sexual intercourse. This assertion could further be justified by the fact that $75 \%$ of patients positive for hepatitis aged
28-47, which is considered to be age of active sexual life among male and female. There was no co-relation between $\mathrm{CD} 4^{+}$values of positive samples and those negative for hepatitis $B$ virus antigens and antibodies. The mean $\mathrm{CD}^{+}$counts obtained for the positive samples were above the threshold values of 200 except for HBsAb (165) and HBeAb (153) which do not stand for active hepatitis infection.

Untreated hepatitis may eventually lead to liver cirrhosis and cancer and subsequent death [25]. There is also an association between hepatitis and elevation of liver enzyme. This finding highlighted some challenges to be encountered in treating patients who were co-infected, especially regarding which HAART regimen to use, how to prevent further hepatic damage, and when to initiate HAART, especially in resource-limited settings with limited ARV options [26].

Twenty percent of the patients- $8 \%$ male and $8 \%$ female were positive for syphilis antibodies. This rate was higher than the $2.7 \%$ projected by the National Behavioral Survey [24] for syphilis infection among Nigerians. Syphilis and HIV are both transmitted sexually and so it is no surprise that a substantial number of people are infected with both agents. HIV has several effects on the presentation, diagnosis, disease progression, and therapy of syphilis. Syphilis may increase the risk of HIV transmission and acquisition by causing genital ulcers. Controversy has surrounded the area of HIV and syphilis co-infection. Some have argued that syphilis have a different clinical presentation and is more aggressive in people with HIV; others suggest there is little difference. Men and women who are sexually active are at a more risk of infection with syphilis. As was observed in this study, positive results for syphilis antibodies were more for patients within the range of 18-57. There was no correlation between the $\mathrm{CD} 4^{+}$counts of positive samples and syphilis infection as the mean $\mathrm{CD} 4^{+}$count for positive samples were 290.5 which were above the threshold value of 200. Major risk factors identified for co-infection with HIV, HBV and syphilis were multiple and unprotected sexual exposure, multiple blood transfusions, and scarification marks.

We have shown that HIV/HBV and HIV/Syphilis co-infections occur in our environment at rates that are comparable with those of other communities. Because of the shared transmission pathways, synergistic effects of these viruses and the impact of HBV and syphilis on presentation, morbidity, and mortality of HIV, screening for HBV should be included in the armamentarium of investigations to be done pre-HAART. Screening for HBsAg must be ensured at the point of screening for HIV, especially in young/middle-aged persons, in widowed/divorced persons, in individuals with a previous history of blood transfusion or scarification marks, and in females.

\section{Acknowledgement}

We would like to acknowledge the support of the staff and management of the AIDS Prevention Initiative in Nigeria (APIN) Clinic, LUTH, Idi-Araba, Lagos, Nigeria. 
Citation: Opara MI, Ogbebor VO, Fasasi MA, Akanmu SA, Bamiro BS, Ayolabi Cl, et al. (2013) Incidences of Hepatitis B and Syphilis Co-Infection with HIV in Antiretroviral Treatment-Naïve Adult Patients Attending APIN Clinic at a University Teaching Hospital in Lagos, Nigeria. J AIDS Clin Res 4: 191. doi:10.4172/2155-6113.1000191

Page 4 of 4

\section{References}

1. Uneke CJ, Ogbu O, Inyama PU, Anyanwu GI, Njoku MO, et al. (2005) Prevalence of hepatitis-B surface antigen among blood donors and human immunodeficiency virus-infected patients in Jos, Nigeria. Mem Inst Oswaldo Cruz 100: 13-16

2. Puoti M, Airoldi M, Bruno R, Zanini B, Spinetti A, et al. (2002) Hepatitis B virus co-infection in human immunodeficiency virus-infected subjects. AIDS Rev 4 : 27-35.

3. Mendes-Corrêa MC, Barone AA, Cavalheiro Nd, Tengan FM, Guastini C (2000) Prevalence of hepatitis $B$ and $C$ in the sera of patients with HIV infection in São Paulo, Brazil. Rev Inst Med Trop Sao Paulo 42: 81-85.

4. Blocker ME, Levine WC, St Louis ME (1999) HIV prevalence in patients with syphilis, United States. Sex Transm Dis 27: 53-59.

5. Alter MJ (2006) Epidemiology of viral hepatitis and HIV co-infection. J Hepato 44: S6-9.

6. Lee HC, Ko NY, Lee NY, Chang CM, Ko WC (2008) Seroprevalence of viral hepatitis and sexually transmitted disease among adults with recently diagnosed HIV infection in southern Taiwan, 2000-2005: upsurge in hepatitis C virus infections among injection drug users. J Formos Med Assoc 107: 404-411.

7. Nyirenda M, Beadsworth MB, Stephany P, Hart CA, Hart IJ, et al. (2008) Prevalence of infection with hepatitis $B$ and $C$ virus and coinfection with HIV in medical inpatients in Malawi. J Infect 57: 72-77.

8. Diop-Ndiaye H, Touré-Kane C, Etard JF, Lô G, Diaw P, et al. (2008) Hepatitis $B, C$ seroprevalence and delta viruses in HIV-1 Senegalese patients at HAART initiation (retrospective study). J Med Virol 80: 1332-1336.

9. Puoti M, Cozzi-Lepri A, Paraninfo G, Arici C, Moller NF, et al. (2006) Impact of lamivudine on the risk of liver-related death in 2,041 HBsAg- and HIV-positive individuals: results from an inter-cohort analysis. Antivir Ther 11: 567-574.

10. Thio CL (2009) Hepatitis B and human immunodeficiency virus coinfection. Hepatology 49: S138-145.

11. Gatanaga H, Yasuoka A, Kikuchi Y, Tachikawa N, Oka S (2000) Influence of prior HIV-1 infection on the development of chronic hepatitis B infection. Eur J Clin Microbiol Infect Dis 19: 237-239.

12. Bodsworth NJ, Cooper DA, Donovan B (1991) The influence of human immunodeficiency virus type 1 infection on the development of the hepatitis $B$ virus carrier state. J Infect Dis 163: 1138-1140.

13. Hadler SC, Judson FN, O'Malley PM, Altman NL, Penley K, et al. (1991)
Outcome of hepatitis B virus infection in homosexual men and its relation to prior human immunodeficiency virus infection. J Infect Dis 163: 454-459.

14. Colin JF, Cazals-Hatem D, Loriot MA, Martinot-Peignoux M, Pham BN, et al. (1999) Influence of human immunodeficiency virus infection on chronic hepatitis B in homosexual men. Hepatology 29: 1306-1310.

15. Gilson RJ, Hawkins AE, Beecham MR, Ross E, Waite J, et al. (1997) Interactions between HIV and hepatitis $B$ virus in homosexual men: effects on the natural history of infection. AIDS 11: 597-606.

16. Krogsgaard K, Lindhardt BO, Nielson JO, Andersson P, Kryger P, et al. (1987) The influence of HTLV-III infection on the natural history of hepatitis $B$ virus infection in male homosexual HBsAg carriers. Hepatology 7: 37-41.

17. Laukamm-Josten U, Müller O, Bienzle U, Feldmeier H, Uy A, et al. (1988) Decline of naturally acquired antibodies to hepatitis $B$ surface antigen in HIV-1 infected homosexual men. AIDS 2: 400-401.

18. Biggar RJ, Goedert JJ, Hoofnagle J (1987) Accelerated loss of antibody to hepatitis $B$ surface antigen among immunodeficient homosexual men infected with HIV. N Engl J Med 316: 630-631.

19. Carter M (2011) Hepatitis B. HIV and AIDS information.

20. Dyer JR, Eron JJ, Hoffman IF, Kazembe P, Vernazza PL, et al. (1998) Association of CD4 cell depletion and elevated blood and seminal plasma human immunodeficiency virus type 1 (HIV-1) RNA concentrations with genita ulcer disease in HIV-1-infected men in Malawi. J Infect Dis 177: 224-227.

21. Hayes RJ, Schulz KF, Plummer FA (1995) The cofactor effect of genital ulcers on the per-exposure risk of HIV transmission in sub-Saharan Africa. J Trop Med Hyg 98: 1-8.

22. Schacker T, Ryncarz AJ, Goddard J, Diem K, Shaughnessy M, et al. (1998) Frequent recovery of HIV-1 from genital herpes simplex virus lesions in HIV-1 infected men. JAMA 280: 61-66.

23. Griemberg G, Ravelli MR, Etcheves PC, Orfus G, Pizzimenti MC (2000) [Syphilis and pregnancy. Prenatal control, seroprevalence and false biological positives]. Medicina (B Aires) 60: 343-347.

24. Integrated Biological and Behavioural Surveillance Survey (2007). HIV/ST Integrated Biological and Behavioural Surveillance Survey. Federal Republic of Nigeria

25. Benhamou Y, Bochet M, Di Martino V, Charlotte F, Azria F, et al. (1999) Liver fibrosis progression in human immunodeficiency virus and hepatitis $C$ virus coinfected patients. The Multivirc Group. Hepatology 30: 1054-1058.

26. Rockstroh JK (2006) Influence of viral hepatitis on HIV infection. J Hepatol 44 S25-27. 